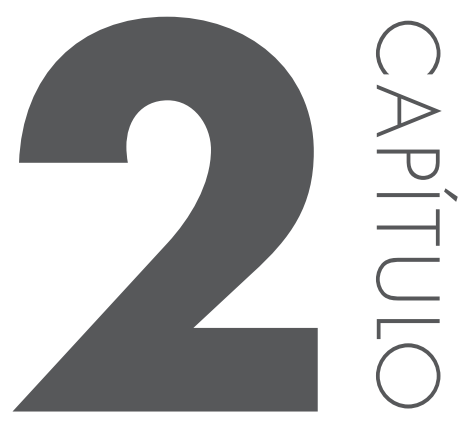

\title{
POLÍTICA PÚBLICA E A INTEGRAC̣ÃO-PRODIGALIDADE LEGISLATIVA. PROBLEMAS PARA A POLÍTICA INDUSTRIAL E DESENVOLVIMENTO SOROCABANAS
}

Francisco Carlos Ribeiro '; Flaviano Agostinho de Lima 2; Sidney Benedito de Oliveira ${ }^{3}$; Celio Olderigi De Conti ${ }^{4}$; Luiz Carlos Rosa ${ }^{5}$; Alexandre Ogusuku 6 ' Fatec Sorocaba José Crespo Gonzales. Correspondencia com os autores: francisco. ribeiro@fatec.sp.gov.br

2 Fatec Tatuí. Presidente da Empresa Municipal Parque Tecnológico de Sorocaba

3 ESAMC-Sorocaba

${ }^{4}$ Fatec Sorocaba José Crespo Gonzales

${ }^{5}$ Fatec Sorocaba José Crespo Gonzales

- Presidente da OAB Sorocaba

\section{RESUMO}

O presente trabalho tem por objetivo refletir sobre as dificuldades da implantação da política pública de forma sistêmica, sugerir o uso de ferramentas de Gestão como PDCA e SWOT em políticas públicas, bem como apontar o problema da Prodigalidade Legislativa. O universo do exemplo se deu com base em legislações do município de Sorocaba. Ao analisar a Política de Tecnologia e Inovação do Município, o artigo propõe, a título de exemplo, uma nova configuração para o Conselho Municipal de Desenvolvimento Econômico e Social transformando-o em Conselho de Desenvolvimento Econômico e de Inovação

Palavras-chave: Políitca Pública. Sorocaba. Prodigalidade Legislativa. Desenvolvimento Econômico e Tecnológico. 


\section{POLÍtICA PÚBLICA}

\subsection{O PROBLEMA EPISTEMOLÓGICO DA "POLÍTICA PÚBLICA" E SUAS IMPLICAÇÕES}

Quando um grupo político que objetiva alcançar o poder, seu plano de governo, se eleito, pressupõe uma agenda política escolhida. É fato que como apontado em "Modelos de Democracia", como o grupo se torna "Estado", tem o poder da caneta, e como o problema de agendas políticas diferentes se apresenta, Lijphart aponta: como fato mitigador, o governar "para o maior número possível de pessoas" (2008 p. 18).

Essa agenda vencedora pressupõe uma ação sobre a realidade. Uma propositura de modificar uma realidade existente ou mantê-la. Também como apontam Sabatier e Jenkins Smith, um item entra ou sai da agenda pública, normalmente por pressão da sociedade e normalmente externo ao ente de governo. (Sabatier p.19-20). Também o conceito de agenda pode ser considerado o "espaço problemático da sociedade" (SERAFIM; DIAS apud BENINI et al. Pg. 314). Ainda temos que:

Um determinado tema é incorporado à agenda quando é identificado como problema passível de se converter em política pública. Esse processo não deve ser entendido como estritamente técnico: a identificação do problema e a construção da agenda envolvem valores e interesses, estão condicionadas a elementos ideológicos e a projetos políticos e refletem as relações de poder entre os atores sociais envolvidos. As políticas públicas, por sua vez, seriam posicionamentos possíveis em relação a essa agenda, dadas as possibilidades teóricas, políticas e materiais apresentadas aos atores que participam do jogo político (SERAFIM; DIAS apud BENINI et al. Pg. 314)

Não existe uma única, nem melhor, definição sobre o que seja política pública. Mead (1995) a define como um campo dentro do estudo da política que analisa o governo à luz de grandes questões públicas e Lynn (1980), como um conjunto de ações do governo que irão produzir efeitos específicos. Peters (1986) segue o mesmo veio: política pública é a soma das atividades dos governos, que agem diretamente ou através de delegação, e que influenciam a vida dos 
cidadãos. Dye (1984) sintetiza a definição de política pública como "o que o governo escolhe fazer ou não fazer". 3 A definição mais conhecida continua sendo a de Laswell, ou seja, decisões e análises sobre política pública implicam responder às seguintes questões: quem ganha o quê, por quê e que diferença faz. (SOUZA, pg. 21)

Então, nesse sentido, quando um chefe do executivo condiciona recursos orçamentários, faz licitação, contrata e constrói uma escola técnica no objetivo de melhorar a educação, sendo a educação valor importante na agenda pública, ele estará fazendo política pública. Assim o conceito desenvolvido como posicionamentos possíveis, entra aqui como definição de política pública. Grosso modo, toda ação administrativa pública no sentido de reunir meios para atender demandas poderíamos, então, chamar de política pública.

Dagnino et. al. apud Dagnino; Greiner pg. 53, dissecam o termo. Segundo eles, Easton define política como "uma teia de decisões que alocam valor", já Jenkins vê a política como "conjunto de decisões Inter-relacionadas "(grifo nosso), concernindo à seleção de metas e aos meios para alcança-las (grifo nosso) dentro de uma situação especificada" Jenkins apud Dagnino et al pag. 53.

A problemática aqui não é a apenas epistemológica e conceitual. É mais profunda. Envolve posturas. Por exemplo: Podemos ter um conjunto de leis que atuam nos sentido de fazer política industrial, leis que tangenciam entre si, mas a sua inter-relação pode ser tênue, pois não foi pensada de maneira integrada, buscando promover sua sinergia. São medidas criadas à luz das demandas e do calor político. E, segundo vimos, política pública pode ser entendida como "posicionamentos possíveis à uma agenda 7". Então todas as ações, boas ou más, visando atender demandas sociais e políticas são, de certa forma, políticas públicas.

Por outrolado, a percepção de política pública, apenas como posicionamento do agente político frente a uma agenda político-social que se apresenta, permite o que chamaremos neste artigo de "prodigalidade legislativa ${ }^{8}$ ", ou seja, dar vazão às demandas dos segmentos sociais produzindo diplomas legais que, em muitas vezes repetem diretrizes, e, em alguns casos, vigoram diplomas legais contraditórios entre si. Diplomas legais que não são aleatórios e, na maioria dos casos, o agente político acredita na pertinência da sua propositura, acredita estar produzindo política pública. E, se considerarmos política pública como ação em defesa de um posicionamento, realmente ele a está produzindo.

\footnotetext{
${ }^{7}$ Nesse sentido iniciamos uma discussão preliminar a esse respeito no artigo "Consolidaç̃̃o Legal e Business Inteligence como ferramentas de Política Industrial"

${ }^{8} 0$ que estamos chamando de prodigalidade legislativa é semelhante ao que Costa (2008, p. 37-42) expõe e por questões de limitação de espaço não discutiremos além do exposto aqui. Vide Costa.
} 
Nessa mesma linha, se o Conselho Municipal de Saúde estabelece que reduzirá a taxas de mortalidade infantil ou de internações do município partindo da hipótese que agirá na conscientização das pessoas mas a conscientização das pessoas, porventura, seja o menor problema, característica não perceptível sem uma diagnose cuidadosa, esse grupo, mesmo que de maneira irreal, acreditará estar fazendo política pública. E, dentro desse contexto de política pública como posicionamento, realmente o estará fazendo. Da mesma maneira busca-se gerar incentivos tributários como política de desenvolvimento ou como política industrial, sendo política pública novamente pensada como posicionamento das suas lideranças políticas e ação na defesa desse posicionamento (advocacy). Realmente teremos, então, política pública.

Esse posicionamento epistemológico traz algumas sérias limitações para a eficácia, eficiência e efetividade das políticas públicas. 1) a crença do agente político ao se posicionar por demandas localizadas e pontuais, estar fazendo política pública. Isso pode ocasionar, por exemplo, projetos de lei (ou atos administrativos) desconexos com outros atos administrativos ou mesmo conflitantes ou paralelos. 2) Pode partir de uma demanda localizada e não de uma diagnose mais apurada, e, portanto, produzindo menos eficiência, menor eficácia e efetividade; 3) Ausência comum de instrumentos de monitoramento, pois as políticas estão difusas e não linearizadas ou integradas de maneira a confluírem em resultados esperados; 4) Falta clareza do modelo de gestão pública a ser adotado e a dificuldade da adesão dos servidores municipais; etc.

\subsubsection{A POLÍTICA PÚBLICA VISTA COMO ATITUDES INTEGRADAS E AS CONTRIBUIÇÕES DA ADMINISTRAÇÃO PARA A SUA EXECUÇÃO}

Como mencionamos, a visão de Jenkin é conjunto de decisões Inter-relacionadas *(grifo nosso), concernindo à seleção de metas e aos meios para alcança-las (grifo nosso) dentro de uma situação especificada)" Jenkin apud Dagnino et al pag. 53.

Ora, quando se supõe metas, estamos supondo ações quantificáveis ou descritíveis bem como tempo e recursos materiais para alcançar os objetivos propostos da política pública. Assim, ao perseguir objetivos-chave de uma política, traçamos as metas, avaliamos as condições materiais necessárias bem como estabelecemos prazo para alcança-las ou prazos para fazermos avaliação do seu estágio, se avançamos ou não.

Nesses termos, faz muito sentido utilizarmos ferramentas como PDCA. Refletindo sobre o fluxograma proposto por Dagnino et al., incluindo a descrição de PDCA de Shewhart- Deming, descrita por Peinado \& Graeml, podemos pensar: 

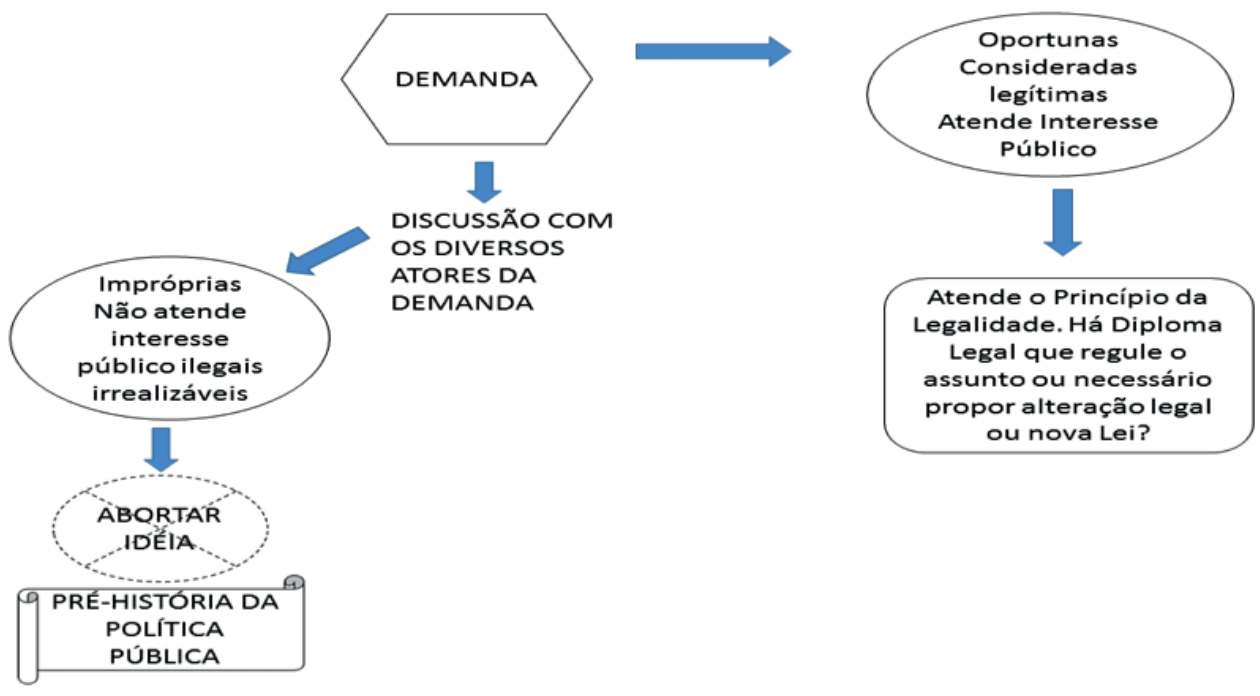

Figura 1 : Pré-História da Política Pública-Elaboração da Política Fonte: Elaboracãóo Própria

Num primeiro momento, o $\mathrm{P}=$ que consubstancia-se em identificação do Problema, Observação, análise para descobrir as causas, Plano de ação (PEINADO; GRAEML p. 557). Vamos fazer alguns comentários. Uma Associação de Bairro pode demandar cuidar da Praça Prêmio Nobel e, como contrapartida, a Associação poder murá-la e utilizá-la como uma área de lazer exclusiva para a população daquele bairro ou mesmo especificamente para o uso exclusivo de seus associados. A demanda, além de ilegal não atende ao interesse público, ainda que atenda ao interesse de uma pequena parcela da população. Desta feita, se não atende nem ao interesse público, não há nem que se observar se atende ao princípio da legalidade. Afinal, o interesse público é que dá legitimidade a todo ato administrativo, descrito em lei ou emanado do pequeno espaço discricionário. A legitimidade do ato administrativo é justamente estar servindo ao interesse público.

Agora, digamos, que aquela mesma Associação demande a instalação de uma nova Unidade Básica de Saúde em seu bairro. Como aponta a Constituição Federal da República em seu artigo $6^{\circ}$ a saúde é um direito social, assim, aquela comunidade solicitar uma nova UBS seria algo natural, uma reivindicação de direito social. Também como a saúde é universalista, qualquer morador de qualquer bairro da cidade poderia se deslocar até essa unidade de saúde. Assim essa nova unidade, mesmo estando inicialmente fora do planejamento municipal de saúde e mesmo não sendo muito adequada à qualidade do gasto público, não há como apontar que ela é ilegal. Também não há como 
desqualificar essa demanda, apontando não ser interesse público, salvo por tentativa de convencimento.

Para os demandantes, a demanda de uma nova unidade básica de saúde será legítima, até que sejam convencidos do contrário. Um chefe do executivo, com visão sistêmica e de planejamento pode, em muitos casos, assumir o ônus político para que a administração pública seja mais eficiente, atenda mais pessoas e seja mais racional e, com isso, dê maior qualidade ao gasto público. Por outro lado, ele também é um agente político com ambições políticas. Se o desgaste, em não atender, for significativo para seu capital político, mesmo sabendo que não "seria tão adequado" ele tomará decisões no sentido de atender ou dar satisfação àquela demanda. Proporá projeto de Lei, se necessário, mesmo que descasado com um plano mais global e sistêmico. Ele fará o trade-off entre melhorar a sua gestão sistêmica e o ônus político. Se o ônus político for inferior aos ganhos de uma administração sistêmica, ele optará por esta. Mas se os danos políticos por não atender uma demanda particularizada em prol de uma administração sistêmica forem maiores que os benefícios desta administração, ele, mesmo sabedor de tal medida não ser tão adequada (portanto mesmo não cumprindo o princípio da eficiência), ele buscará o atendimento da demanda, pois antes, está seu microprojeto de poder.

Em se tratando de participante do poder legislativo, não ocorre diferentemente. Salvo o fato de que se tem maior facilidade de fazer proposituras, mesmo que ela seja considerada inconstitucional, (seja pela própria Assessoria Jurídica da Casa, que a vetará, seja se, aprovada, por uma ADIN (Ação Direta de Inconstitucionalidade) na qual ele pode dizer, "eu tentei, mas não foi possível” e preservar sua clientela política, mesmo que a princípio o mesmo saiba que é natimorta. Mas a necessidade de dar vazão à demanda de seus eleitores é premente por que ele (o legislador) não tem o poder do orçamento e dos recursos materiais que o Executivo tem, então a crença dos seus eleitores de que ele está fazendo o melhor possível é seu maior capital. Daí decorre um dos motivos da prodigalidade legislativa.

Mas vamos supor que, como apontamos no quadro acima, a demanda se mostre legítima: a primeira questão na administração pública é verificar: "Atende o Princípio da Legalidade. Há Diploma Legal que regule o assunto ou necessário propor alteração legal ou nova Lei?”

Em ambos os casos, temos que incluir na nossa problemática os recursos humanos para isso, ao utilizar as ferramentas PDCA, SWOT e como eles contribuiriam para a eficiência no desenho e aplicação de uma política pública. 


\subsubsection{CONSIDERAÇÕES SOBRE O CAPITAL HUMANO PARA A CONSTRUÇÃO DE UMA POLITIICA PÚBLICA SISTÊMICA E CONSISTENTE}

A elaboração e aplicação de uma política pública seja já sob a égide de um diploma legal vigente, seja para a construção de um novo, mais apropriado, passa pela interação de diversos atores (policy markers e stakeholders). Iremos separar, de forma arbitrária os grupos, bem como as denominações foram escolhidas com base em perfis, e tais características baseadas em experiência empírica dos autores desse artigo e não numa classificação dada pela literatura ${ }^{9}$.

Vamos começar com os demandantes de uma política, ou os chamados públicos (stakeholders). Normalmente as demandas surgem de grupos de pessoas, mas a sua participação efetiva é de pessoas que possuem tempo hábil para atuar nelas, em outras palavras que já tem os meios de subsistência garantidos, sejam acadêmicos e profissionais de ONGs que exercem função remunerada para isso, ou que atuam nelas secundariamente mas já com atividade profissional bem resolvida. Ocorre que cada vez mais, tem sido crescente a consciência da importância do associativismo como instrumento de pressão política. Por exemplo, em Sorocaba temos criada a USABS, que nada mais é que a União das Associações de Bairro de Sorocaba, bem como o surgimento de associações, como o Instituto Defenda Sorocaba integrando outros segmentos, mesmo de classe ${ }^{10}$. Ou seja, uma instância articuladora formada por outras instâncias articuladoras. Assim o número de pessoas que se articulam para demandar políticas públicas cresce diariamente. Há que se notar que cresce cada vez mais a participação popular em Fóruns, tais como Conferências Municipais, etc., ao lado do fortalecimento das inúmeras redes sociais de maneira que os stakeholders possam se manifestar.

Podemos separar esses demandantes, grosso modo, em dois grupos ${ }^{11}$ :

A) STAKEHOLDERS DE EXCELÊNCIA EMPÍRICA E DE FRACA PERCEPÇÃO EM POLÍTICAS PÚBLICAS

Esses demandantes de política pública estão na linha de frente do problema. Vivenciam o problema. Aqueles que não o vivenciam diretamente (normalmente acadêmicos) tem visão teórica e pratica do problema. Sabem que é necessário fazer algo, sabem que o problema deve ser atacado, e algumas vezes sabem como atacá-lo. Mas não têm a menor ideia sistêmica de administração pública e muito menos as bases do direito administrativo que rege a coisa pública. Nesse grupo, também existem advogados, mas que em geral, estudaram na sua graduação Direito Administrativo mas lhes faltam conhecimento de outras

\footnotetext{
${ }^{9}$ Obviamente a realidade é mais complexa e existem degrades entre diversos tipos. Mas é uma classificaçã̃o aceitável para nossa análise.

${ }^{10} \mathrm{http}: / /$ defendasorocaba.com.br/

${ }^{11}$ Aqui estamos partindo da divisão de stakeholders bem-intencionados. Deixamos de fora os "Pilantropos" que buscam apropriar-se licitamente ou ilicitamente do dinheiro público.
} 
ferramentas teóricas como teorias da justiça, princípios de focalização do gasto público, conhecimentos do problema da causação circular da pobreza cumulativa e como se propõe uma política pública de maneira robusta e, ao mesmo tempo, preservando a não-discricionariedade do administrador público. Isso pressupõe estudos que em muitos casos não são da área de atuação deles. Isso falando de advogados que estudaram, obrigatoriamente na sua graduação, Direito Administrativo. Imaginem o cidadão comum? Esses stakeholders sabem descrever e caracterizar o problema com precisão ímpar, mas são reféns de terceiros quanto às formas de resolução deles na esfera do poder público. Aqui se insere também muitos acadêmicos que desconhecem (não o conhecem com a devida proficiência básica) o Direito Administrativo e, portanto, os princípios da administração pública e sua aplicação adequada.

B)STAKEHOLDERS COM CONHECIMENTO NA LINHA DE FRENTE DO PROBLEMA E VISÃO SISTÊMICA, TÉCNICA E JURÍDICA DE ADMINISTRAÇÃO PÚBLICA

Oxalá um dia isso venha a ser maioria. Mas hoje infelizmente, continua muito pequeno. Pessoas que tem conhecimento na linha de frente do problema, e ainda conhecem bem como funciona os meandros da administração pública e, também, as bases do Direito Administrativo, de forma que conseguem avaliar tecnicamente se os projetos de lei formulados atendem não só a resolução do problema, mas contribuem para a qualidade do gasto público, e se é feito de maneira menos discricionária possível, de forma a preservar o interesse público. Esse seria o público ideal para pertencer aos Conselhos Municipais, pois, hoje, pessoas de altíssimo gabarito que pertencem a esses Conselhos, na maioria dos casos, não tem o mapa completo de navegação de todas essas nuances da administração pública. Os acadêmicos, cidadãos ou lideranças das mais diversas que dominam essas ferramentas em conjunto contribuem bastante para a elaboração e implantação de políticas públicas mas, o número dessas é bastante reduzido.

\section{C)AGENTES POLÍTICOS}

Chamamos de agentes políticos (policy makers) aqueles que conduzem (governam) a esfera pública ${ }^{12}$. No caso em tela, estamos praticamente chamando de agentes políticos o staff de primeiro escalão (Secretários de Governo) mas isso pode ser estendido a diversos cargos de confiança de natureza basicamente política.

Desses agentes políticos, podemos dividi-los basicamente:

- OS DE ORIGEM INTERNA: 
São aqueles que são funcionários de carreira, portanto, internos do quadro de administração do poder público, mas que são escolhidos por critérios de confiança e alinhamento partidário ou de coalizão. Podem ser escolhidos também por sua competência técnica e administrativa. Mas, normalmente, o alinhamento político e ou de coalizão é fundamental para a escolha.

Por pertencerem aos quadros internos da administração, conhecem bem as mazelas e potencialidades de ação. Normalmente (mas nem sempre) sabem da importância de uma administração sistêmica, bem como a relevância do arcabouço legal para a perenidade de uma política pública. Não obstante a isso, sua principal função é atender as expectativas de cumprimento da agenda política do chefe do executivo. Para isso, será mais ou menos técnico, na medida das suas convicções, mas sempre condicionada ao atendimento da agenda política do chefe do Executivo.

- OS MIGRANTES DO LEGISLATIVO:

Esses (membros do poder legislativo, Vereadores, que ocupam Secretarias) conhecem muito bem os meandros políticos. Não necessariamente conhecerão a gestão pública de maneira técnica. São sensíveis e cumpridores da agenda do Executivo. Terão sempre a predominância da agenda, pois migraram do legislativo, provenientes do mesmo partido do chefe do Executivo ou de partidos coligados. Então a agenda política é o capital maior. É mais sensível a prodigalidade legislativa e ações pontuais que atendam a agenda política. O comprometimento com uma gestão sistêmica pode haver, mas não será, necessariamente, o objeto a ser perseguido. Objeto a ser perseguido será a agenda. Perfil mais propenso a medidas pontuais e a prodigalidade legislativa devido à sua natureza.

- OS GESTORES PÚBLICOS DO SETOR PRIVADO:

Normalmente esse segmento é formado por profissionais com capacitação em administração pública e governo, mas que atuam no setor privado devido a inúmeros motivos. Conhecem os princípios das políticas públicas sistêmicas, conhecem os mecanismos e a lógica da administração pública presentes no Direito Administrativo. Conhecem também a racionalidade e a eficiência das praticas de gestão, correntes no setor privado. Não é impossível encontrar esses profissionais mas são em reduzido número, uma vez que, embora conheçam políticas públicas e gestão sistêmicas delas, estejam no setor privado. Isso não é comum.

- OS EMPREENDEDORES VOLUNTARISTAS E DOIDIVANAS DO SETOR PRIVADO: Já esses são encontrados com frequência ocupando a função agentes políticos. São, normalmente, profissionais do setor privado ${ }^{13}$, que, acostumados com a agilidade do setor privado, chegam sedentos de promover "agilidade e 
desburocratização". Mas muito deles, sequer tem a menor noção de Direito Administrativo, e não chegam a perceber que, muito do rito processual da administração pública é necessário. Como lembra o mestre Helly Lopes Meirelles:

$\mathrm{Na}$ Administração Pública não há liberdade nem vontade pessoal. Enquanto na administração particular é licito fazer tudo o que a lei não proíbe, na Administração Pública só é fazer o que a Lei autoriza. A lei para o particular significa "pode fazer assim"; para o administrador público significa "deve fazer assim (Meirelles; Aleixo; Burle Filho; 2012, p. 89)

Não entendem, os mesmos, que racionalidade e eficiência são muito bem-vindas à administração pública (cumprindo o Princípio da Eficiência da Administração Pública), entretanto, não se pode fazê-lo aos atropelos. Muitos não percebem que, uma das maiores proteínas do setor privado que é a livre iniciativa, ou seja a discricionariedade, fazemos como queremos, quando queremos e para quem queremos, transmuta-se, quando no setor público, no seu maior carcinoma, pois, essa discricionariedade, justamente por tratar com a rés pública, tem de ser reduzida ao mínimo ${ }^{14}$. No entanto, se doidivanas, querem explorar justo as brechas ou querem evitar planos consistentes de políticas públicas buscando seu enriquecimento pessoal.

Acostumadocomaagilidade dosetor privado,ouesseempreendedorestudará Direito Administrativo, entenderá sua essência e a aplicará racionalizando processos, ou ficará revoltado de como "as coisas na administração pública não andam" (expressão comum deles), ou ainda, atropelará procedimentos gerando problemas jurídicos e pessoais para o mesmo o expurgando do setor público.

Sem embargo dessa problemática, também terá de atender a demanda da agenda política do grupo político dominante.

\section{- LEGISLADORES:}

Sua principal função é propor e avaliar projetos de Lei. São movidos em primeiro plano pelas demandas dos seus eleitores. A propositura de lei não necessariamente é fruto de uma política pública perene, pactuada com o Executivo ou pensada de maneira sistêmica.

\footnotetext{
${ }^{13}$ Muitos deles extremamente competentes no setor privado, empreendedores na melhor acepção, profissionais de excelência e boa reputação, mas voluntaristas. Os doidivanas se aplicam mais aos parasitas do setor privado, àqueles que, fracassando no setor privado acreditam ter "uma chance" de enriquecer-se com os recursos públicos ao ocupar Secretarias e postos importantes na Administração Pública.

${ }^{14}$ Não à toa que a fórmula de Klitgaard é $C=M+D+0-A C$ sendo $D$ a discricionariedade. Quanto maiora discricionariedade maior a corrupcão. 0 texto referenciado de Klitgaard não tem 0 0, de Opacidade, ou seja, poucos instrumentos de informaç̃ão. Mas foi incorporado pois, quando menor diversidade de fontes de informação maior tende a se ter corrupçã̃o. Obviamente, como uma empresa qualquer, a imprensa será seletiva na medida de preservar seus interesses econômicos. Daí a importância da diversidade. Mas mesmo com tantos problemas, ainda a máxima de Mandeville vale: vícios privados benefícios públicos.
} 
A corroboração do que falamos se expressa pela existência do significativo número leis aprovadas que são declaradas inconstitucionais e, mais ainda, leis que, aprovadas em plenário, já tinham recebido da sua própria Secretaria Jurídica, o parecer de inconstitucionalidade. Tal característica é corrente.

Assim não é expressivo o número de legisladores que vê e atua sobre a política pública de maneira sistêmica. Isso remete refletir a quantidade de leis elaboradas que, ou foram declaradas inconstitucionais ou quantas não chegaram a se transformar em políticas públicas e como poderia ser diferente, ou seja se os poderes atuassem mais sistemicamente.

Cremos ter caracterizado os agentes políticos.

\section{D) QUADROS DO FUNCIONALISMO}

Não vamos estabelecer uma divisão funcional. Mas arbitrariamente vamos fazer uma divisão comportamental. Nesse sentido temos:

- os AUTARQuistas:

Chamamos de autarquistas, aqueles profissionais de carreira que conhecem os meandros da administração, conhecem as sensibilidades, vaidades e questões corporativas da máquina administrativa e tentam abortar iniciativas propostas pelo agente político a que estão submetidos por que tais iniciativas provocarão polêmica com outros pares (normalmente de outras secretarias ou agências de governo ou empresas públicas, e os obrigarão a sair da sua zona de conforto). Diriam assim "Afinal, os agentes políticos vêm e vão, mas nós ficamos inclusive com as rusgas das polêmicas provocadas com os demais pares". Melhor então, medidas mais tímidas, que "a Secretaria em questão tenha pernas para cumprir", que "não envolvam outra Secretaria”. Essa barreira para ser transposta, necessitará de uma predisposição, conhecimento e vontade maior do agente político para não "cair no canto da sereia" dos autarquistas.

- OS INERCIALISTAS:

Chamamos aqui de inercialistas os profissionais de carreira concursados, que, conhecedores das regras de evolução funcional, sabem das potencialidades e das limitações da meritocracia da administração. São profissionais que fazem com zelo (uns mais outros menos) sua tarefa e cumprem a norma existente. Muito deles, se inquerido por que fazem aquele procedimento lhes responderão "Porque a lei manda!". Mas se avançarmos na pergunta: por que a lei manda? Qual o espírito de proteção à rés pública que o legislador teve ao elaborar essa lei? Muitos deles não saberão responder e outros tantos nem sequer irão querer saber o porquê. Continuarão a cumprir suas funções com esmero (uns mais outros menos) e mudarão de procedimento quando receberem a orientação e informação que a Lei mudou e seguirão a nova lei com diligência, atuando 
praticamente de maneira inercial. É preciso ter em mente que parte da política pública será executada por parcelas desse quadro funcional.

- OS NORMALISTAS COMPULSIVOS:

Em grau, diríamos que esse é o segundo colocado em perniciosidade da Administração Pública: O normalista compulsivo. Aquele que, tendo espaço discricionário, ou problemas se apresentando a ele para que seja dada adequada normalização, é pródigo em fazer normas, muitas destas, elaboradas sem um estudo adequado ou sem as condições materiais suficientes para seu cumprimento. Podemos dizer que ele tem uma produção "intestinal” de normas. Tais normas muitas vezes com vício de origem, ou seja, já nascem com prazos e procedimentos cujo cumprimento é uma quimera. Embora isso não seja uma característica exclusiva desses membros do quadro do funcionalismo (há uma miríade de leis, e decretos, seja de origem legislativa ou executiva cujos prazos prescrevem e não se realizam), esse tipo de profissional é bastante prejudicial à política pública perene e sistêmica por que coloca em descrédito, muitas vezes uma política pública e mesmo uma gestão. Muitas vezes tal prodigalidade de normas (realistas e irrealistas) vem da necessidade de demonstrar poder, de marcar seu território nos recônditos da Administração.

\section{- OS FEUDALISTAS:}

Esse sim o mais pernicioso e perigoso grupo a enfrentar. É quase a antítese dos normalistas compulsivos.

Esses ocupantes de espaços de poder, percebendo situações não regulamentadas (onde se pode exercer o poder discricionário) fazem questão de não normatizá-las e, por consequência, em muitos casos, não dar perenidade às políticas públicas pois, ao manter a discricionariedade, mantém espaços de poder e de negociação com demais agentes internos e externos. Não à toa que Klitgaard apontou que onde sobra discricionariedade sobra corrupção. A falta de regras claras determinando o que se deve fazer e como fazer, permite a discricionariedade e discricionariedade sem controle social é um passo largo à corrupção.

- OS GeSTORES DE POLÍTICAS PÚblicAs:

Por fim, por justiça é necessário elencar aqueles que são apaixonados pela busca incessante da qualidade do gasto público. Esses veem a política pública sistêmica, de avaliação de resultados como necessárias e fundamentais para a qualidade do gasto público. Tem forte impermeabilidade a conflitos e, portanto, disposição a lutar por implantação e perenidade de políticas públicas. Inconformados com os processos descontínuos ou caóticos encontrados nas tratativas públicas. 


\subsubsection{DCA E SWOT NA GESTÃO PÚBLICA}

Então, além de identificar o problema, descobrir as causas, é preciso analisar o marco regulatório bem como a necessidade de muda-lo ou de criar um novo dispositivo legal, avaliar os públicos envolvidos e como lidar com ele. O P do PDCA exige um refinamento maior.

As estratégias de elaboração e execução da política (D) também terá que ser ciente do perfil de todos os públicos envolvidos bem como os interesses de curto e longo prazo do executivo e, por consequência, dos agentes políticos. $\mathrm{O}$ controle da aplicação da política será dado pelo que a própria política pública na sua formulação legal estabeleceu. Caso o diploma legal da política não contemple as formas de controle, ficará a cargo de uma certa discricionariedade não recomendável para a Administração que implicará na influência da avaliação (A).

De qualquer maneira, o PDCA permite analisar a política como ciclo e é uma ferramenta útil na formulação da política pública. Da mesma maneira, a análise SWOT ${ }^{15}$ face todos os públicos envolvidos, se torna uma ferramenta poderosa para ver as reais possibilidades de implementação de uma política pública.

Os usos dessas ferramentas, mais a percepção de que a política pública deve ser sistêmica evitaria muito do que estamos chamando de prodigalidade legislativa.

\section{PRODIGALIDADE LEGISLATIVA: UMA AMOSTRA DO MUNICÍPIO DE SOROCABA}

Como amostra da prodigalidade legislativa, vamos utilizar três pares de leis e comentá-las, de maneira breve, uma vez que usamos bastante espaço para discutir os meandros da administração pública que são importantes ressaltar quando pensamos em política pública. As leis são: Lei 9672/2011, que “dispõe sobre a organização do Sistema de Inovação de Sorocaba e sobre medidas de incentivo à inovação tecnológica, à pesquisa científica e tecnológica, ao desenvolvimento tecnológico, à engenharia não-rotineira e à extensão tecnológica em ambiente produtivo, no município de Sorocaba,”; Lei 9892/2011, que "autoriza a Constituição da Empresa Pública "Empresa Municipal Parque Tecnológico de Sorocaba"; Lei 9114/2010 que “dispõe sobre o Estatuto Municipal da Microempresa da Empresa de Pequeno Porte" (revogada pela Lei 9449/2010); Lei 9449/2010 que “dispõe sobre o Programa de Incentivos 
para o Desenvolvimento da Economia Solidária, Turística e Tecnológica de Sorocaba, com tratamento favorecido, diferenciado e simplificado aos Micro Empreendedores Individuais, Microempresas e Empresas de Pequeno Porte de Sorocaba", e finalmente as leis 10.228/2012 que "dispõe sobre a criação do Fundo de Apoio às Cooperativas de Reciclagem de Sorocaba, e a 10.388/2013 que "Institui o Programa Municipal de Coleta Seletiva dos resíduos reutilizáveis e recicláveis domiciliares mediante a inclusão formal dos catadores e catadoras. Vejamos

a) Lei $9672 / 2011$.

Nessa Lei, destacamos:

Art. $1^{\circ}$ Esta Lei estabelece medidas de incentivo à inovação tecnológica, à pesquisa científica e tecnológica, ao desenvolvimento tecnológico, à engenharia não-rotineira, à informação tecnológica e à extensão tecnológica em ambiente produtivo ou social, visando alcançar a capacitação e o desenvolvimento industrial e tecnológico internacionalmente competitivo do município de Sorocaba...

Art. $7^{\circ}$ Fica instituído o Conselho Municipal de Ciência, Tecnologia e Inovação - CMCTI, organismo consultivo de apoio ao Poder Executivo Municipal, com a finalidade de promover a discussão, a proposiç̧ão e o acompanhamento das políticas públicas de Ciência, Tecnologia e Inovação, de interesse do Município, bem como apoiar e incentivar o desenvolvimento científico, tecnológico e à inovação, com vistas ao desenvolvimento sustentável do Município.

Ainda na mesma lei, eu seu artigo 10 temos, que compete, ao Conselho Municipal de Ciência Tecnologia e Inovação:

$\mathrm{V}$ - contribuir com as políticas públicas da Secretaria Municipal de Desenvolvimento Econômico por meio de programas e instrumentos que promovam a transferência de tecnologias inovadoras e incrementais ao setor produtivo, com ênfase em médias, pequenas e microempresas e no empreendedorismo social, para a geração de postos de trabalho e renda;

VII - propor ao Executivo Municipal os orçamentos e os planos anuais e plurianuais de ciência e tecnologia, nos quais estarão fixadas as diretrizes e prioridades que nortearão as aplicações dos recursos do Fundo Municipal de Apoio à Ciência, Tecnologia e Inovação de Sorocaba - FACITIS; 
E, por fim:

Art. 22 Fica o Executivo Municipal autorizado a criar o $\underline{\text { Instituto }}$ de Inovação Científica e Tecnológica de Sorocaba - IICTS, órgão da administração pública municipal, direta ou indireta, que tenha por missão institucional executar, dentre outras, atividades de pesquisa, desenvolvimento tecnológico e/ou inovação

b) Lei $9892 / 2011$

Art. $7^{\circ}$ A Empresa Municipal Parque Tecnológico de Sorocaba terá por objeto gerenciar, organizar e estruturar o Parque Tecnológico de Sorocaba - PTS para promover e estimular as atividades econômicas do Município, através do desenvolvimento da infraestrutura, da base empresarial, da ciência e da tecnologia do PTS, visando contribuir para o desenvolvimento socioeconômico e ambiental de Sorocaba e da sua população

E no Estatuto Social da Empresa Municipal parque Tecnológico estabelecido pelo Decreto 19826/2012, dispõe:

\2 ${ }^{\circ}$ São atividades a serem desenvolvidas pela Gestão Executiva de Ciência e Tecnologia do PTS

i) Promover o desenvolvimento científico e tecnológico objetivando a melhoria das condições de vida de sua população, notadamente no que se refere aos padrões de saúde, educação, habitação, transporte e meio ambiente;

j) Promover o desenvolvimento científico e tecnológico objetivando o fortalecimento e a ampliação da base técnico-científica existente no Município, constituído por entidades de ensino, pesquisa e prestação de serviços técnicos especializados e por unidades de produção de bens e serviços de elevado conteúdo tecnológico;

k) Promover o desenvolvimento científico e tecnológico objetivando a criação de emprego e renda, mediante o aumento e a diversificação das atividades econômicas que tenham por base a geração e aplicação de conhecimento técnico e científico;

1) Promover o desenvolvimento científico e tecnológico objetivando o aprimoramento das condições de atuação do Poder Público 
Municipal, notadamente no que se refere à identificação e ao equacionamento das necessidades urbanas e ao aproveitamento das potencialidades do município

Quem deve promover a Ciência e Tecnologia, a Empresa Municipal Parque Tecnológico ou o Conselho Municipal de Ciência Tecnologia e Inovação? Ou ambos? Se a Lei criou a Empresa Municipal Parque Tecnológico de Sorocaba, qual seria então a função do Instituto de Inovação Científica e Tecnológica de Sorocaba - IICTS?

Há que se notar que a nomeação dos membros do Conselho Municipal de Ciência, Tecnologia e Inovação, ocorreu através do Decreto 19.977. de 4 de junho de 2012. Até o encerramento desde artigo (abril/2015) não foi realizada a primeira reunião e alguns de seus membros representantes das Secretarias de Governo já deixaram o poder público. Esse é um bom exemplo da falta de política pública sistêmica. Mas os exemplos a seguir indicam maior caracterização do que estamos chamando de prodigalidade legislativa.

c) Lei 9114/2010 e Lei 9449/2010.

Essas, vamos contrapô-las por que o exemplo é marcante.

Lei 9114/2010

$\$ 3^{\circ}$ Microempresa (ME) é o empreendimento societário ou individual, com receita bruta anual igual ou inferior a $\mathrm{R} \$$ 240.000,00 (duzentos e quarenta mil reais).

Lei $9449 / 2010$

I - microempresa (ME) é o empreendimento societário ou individual, conforme disposição em lei complementar federal;

Lei $9114 / 2010$

$\$ 4^{\circ}$ Empresa de Pequeno Porte (EPP) é o empreendimento societário ou individual, com receita bruta anual superior a R\$ $240.000,00$ (duzentos e quarenta mil reais) e igual ou inferior a R $\$$ 2.400.000,00 (dois milhões e quatrocentos mil reais).

Lei $9449 / 2010$

II - empresa de pequeno porte (EPP) é o empreendimento societário ou individual, conforme disposição em Lei Federal Complementar. Lei $9114 / 2010$

Art. $7^{\circ}$ Toda concessão deve estar alicerçada no princípio da legalidade, não havendo impeditivos para que o Poder Público Municipal exerça suas funções de incentivo da atividade econômica, nos termos do Título VII da Constituição Federal, desde que seja 
atendida a exigência de atuação planejada e transparente, conforme previsto na Lei de Responsabilidade Fiscal (LC 101, de 04/5/00), sobretudo em seus art. $1^{\circ}$ e 14 .

Lei 9449/2010

Art. $2^{\circ}$ Toda concessão deve estar alicerçada no princípio da legalidade, não havendo impeditivos para que o Poder Público Municipal exerça suas funções de incentivo da atividade econômica, nos termos do Título VII da Constituição Federal, desde que, seja atendida a exigência de atuação planejada e transparente, conforme previsto na Lei de Responsabilidade Fiscal.

Há que se ressaltar quea Lei 9449/2010 revogou expressamentea 9114/2010. No entanto, ao observamos o parecer da Secretaria da Câmara Municipal sobre o projeto de Lei 268/2009, o mesmo relata sobre inconstitucionalidade do mesmo, a Comissão de Redação e Justiça aponta ter vicio de origem. Mesmo assim a Lei foi aprovada e sancionada pelo Poder Executivo. Foi o próprio Poder Executivo que apresentou o substituto depois. Soma-se ao fato curioso, é que os proponentes eram do mesmo partido e poderiam ter elaborado um único documento e pensado a política de forma sistêmica. Esse caso é uma forte pista do que estamos chamando a atenção.

d) Lei 10388/2013

E o exemplo extremo, duas Lei, criando o mesmo Fundo de Amparo à Coleta Seletiva apenas por nomes diferentes:

Lei 10388/2013 que "Institui o Programa Municipal de Coleta Seletiva Solidária” temos em seu artigo:

Art. 10. Visando à universalização do serviço prevista na Lei Federal $n^{\circ} 11.445 / 2007$, fica instituído o FMUCS - Fundo Municipal para Universalização da Coleta Seletiva, constituído com os recursos provenientes de:

I - $100 \%$ do custo mensal das toneladas de resíduos reutilizáveis e recicláveis domiciliares, não recolhidos pela coleta convencional e que foram coletados pelas cooperativas;

II - $100 \%$ do custo mensal das toneladas de resíduos reutilizáveis e recicláveis domiciliares, provenientes da coleta convencional, que deixaram de ser aterrados;

III - $3 \%$ do valor pago às empresas contratadas para a coleta e destinação do lixo urbano no aterro sanitário.

Parágrafo único. Os valores para constituição do fundo municipal 
anunciado neste artigo estarão referenciados nos preços estabelecidos nos contratos em vigor, seus ajustes e aditamentos, referentes à coleta e destinação final dos resíduos sólidos domiciliares em aterros sanitários.

E na Lei 10228/2012 temos:

Art. $1^{\circ}$ Fica instituído o Fundo de Apoio às Cooperativas de Reciclagem de Sorocaba - FACRES, junto a Secretaria de Parcerias - SEPAR, com objetivo de desenvolver os projetos que visem à manutenção dos serviços das Cooperativas de Reciclagem, que façam parte do Programa Municipal de Coleta Seletiva.

Creio que esses exemplos nos dão pistas importantes sobre prodigalidade legislativa. Há que se observar que a Lei 10.388/2013 foi declarada Inconstitucional através da ADIN 0114 982-76.2013.8.26.0000. Bom lembrar que ambas as leis sobre Coleta Seletiva foram aprovadas pela Câmara Municipal.

Já expusemos longamente os problemas inerentes à falta de uma política pública sistêmica, a prodigalidade legislativa, e também do problema da intencionalidade às vezes não clara, na política pública.

Ao praticar uma política pública, inclusive industrial, entendemos importante primarmos por evitar a política pública sem aplicação sistêmica, bem como a possibilidade de acompanhar e avaliar políticas públicas.

É nesse sentido que estamos sugerindo um novo formato para o Conselho de Desenvolvimento Econômico.

\section{O CONSELHO MUNICIPAL DE DESENVOLVIMENTO ECONÔMICO E SOCIAL. UMA PROPOSTA DE REVISÃO}

A Lei Municipal 4.394, de 14 de outubro de 1993, que dispôs sobre criação do Conselho Municipal de Desenvolvimento Econômico e Social - C.M.D.E.S, foi modificada pela Lei Municipal 5546/98 de 12 de janeiro de 1998, estabelece que, é função do Conselho Municipal de Desenvolvimento Econômico e Social do município, excluídas as atribuições de gestão interna (criação de regimento, reuniões etc.): 
a) assessorar o Poder Executivo na definição da política de desenvolvimento econômico do município;

b) promover discussões entre diversos representantes da sociedade civil, buscando captar as tendências de oportunidades e necessidades para o desenvolvimento econômico do município;

c) recomendar ao Poder Executivo aprovação da redução ou isenção de impostos e taxas, bem como da concessão de benefícios às empresas industriais e de serviços, instaladas ou que venham se instalar no município;

Salvo a nomenclatura, ou seja, o nome do Conselho de Desenvolvimento Econômico e Social, o texto da Lei 5546, não fala absolutamente nada de desenvolvimento social. Por outro lado, a Lei 10589/2013, que alterou a estrutura administrativa da Prefeitura, transformou a Secretaria da Cidadania em Secretaria de Desenvolvimento Social. Já as atribuições da Secretaria da Cidadania, eram: "Secretaria da Cidadania: apoio às ações sociais no Município, promovendo o bem-estar social através de programas direcionados à família, à criança e ao adolescente, ao deficiente, ao idoso e à mulher.”

Dessa maneira, não há que falar em Conselho de Desenvolvimento Econômico e Social uma vez que: a) A lei que cria o Conselho de Desenvolvimento Econômico e Social não traz em seu corpo nenhuma menção a preocupação social, mesmo que essa seja uma preocupação inerente e louvável do CMDES, 2) É atribuição da Secretaria de Desenvolvimento Social, promover o Desenvolvimento Social, inclusive interessante ter até um Conselho de Desenvolvimento Social para seu apoio.

Por outro lado, não há que se falar de desenvolvimento econômico, sem falar em política de inovação. Da mesma maneira, encontra-se sobreposição de funções, e o Conselho de Ciência e Tecnologia, descolado do Conselho de Desenvolvimento Econômico e Social sem contar que cabe à Empresa Municipal Parque Tecnológico de Sorocaba "Promover o desenvolvimento científico e tecnológico objetivando o fortalecimento e a ampliação da base técnico-científica existentes no Município”.

Por isso neste artigo e em discussões estamos, apontando como exemplo para reflexão, uma nova configuração. O Conselho de Desenvolvimento Econômico e Social passaria a ser o Conselho de Desenvolvimento Econômico e Inovação (extinguindo-se o "Conselho de Desenvolvimento Científico e Inovação").

O Conselho seria composto por 5 (cinco) Câmaras Técnicas. Cada representante da Câmara Técnica comporia o núcleo decisório do Conselho. 
Assim as nomeações ocorreriam para os membros das Câmaras Técnicas.

A) CÂMARA DE ASSESSORIA TÉCNICA-JURÍDICA, DE HARMONIZAÇÃO LEGAL E DE POLÍTICAS DE INCENTIVO

Objetiva dar orientar e estudar problemas de legislação de maneira a verificar conflitos e sobreposições de atribuições constantes em diplomas legais municipais, de maneira a harmonizar a legislação no sentido de dar mais eficácia às políticas públicas de desenvolvimento econômico do município, bem como sugerir os textos legais de Políticas de Incentivo Fiscal bem como demais formas de incentivo propostas por demais Câmaras que gerem incentivos ao desenvolvimento econômico de maneira estratégica ao município. Câmara que poderia ser composta basicamente pelo setor empresarial e instituições empresariais e comerciais e poder público. Participação da OAB por excelência nessa Câmara.

B) CÂMARA DE CIÊNCIA, TECNOLOGIA E INOVAÇÃO E EMPREENDEDORISMO.

Essa Câmara, com a participação e coordenação da Empresa Municipal Parque Tecnológico, reuniria aqui, também, representante de Universidades, enfim, todos os membros existentes hoje no Conselho Municipal de Tecnologia e Inovação, de maneira a resolver parte duplicidade de atribuições. Desta maneira seria extinto o Conselho de Ciência e Tecnologia e Inovação (salvo se a lei foi criada para atender legislação estadual e federal). Se inconveniente tecnicamente e politicamente a extinção de tal Conselho, ao menos a Empresa Municipal Parque Tecnológico (ou seu representante) mais o Conselho de Inovação e Tecnologia fariam, por excelência parte dessa Câmara Temática no CMDEI.

Também integram essa Câmara SEBRAE nessa Câmara Temática e outros organismos vinculados à Microempresa.

\section{C) CÂMARA DE CAPITAL HUMANO.}

Responsável por estudar as demandas e ofertas de capital humano necessário ou ideais ao desenvolvimento econômico do município. Aqui também se insere a mesma questão. A Comissão Municipal de Emprego, Poe excelência, poderia ocupar essa Câmara ou dependendo da conveniência e oportunidade legal, fundir-se nesse grande Conselho de Desenvolvimento Econômico e Inovação.

D) CÂMARA DE ANÁLISE DE CONJUNTURA, CENÁRIOS E INFORMAÇÕES ESTRATÉGICAS (BI)

Responsável por fazer análise de conjuntura, cenários e informações 
estratégicas. Maior participação efetiva de organismos como o Corecon, FIESP, etc.

\section{E) CÂMARA TEMÁTICA DE POLÍTICAS DIFUSAS}

Câmara composta, por excelência, por membros do Condema ${ }^{17}$ ou seu representantes, inclusive as demandas desse conselho poderiam ser levadas para grupos de discussão ao próprio CONDEMA., do COMAPA e fórum específico para discussão de políticas difusas que impactam sobre o desenvolvimento econômico do município.

A forma de deliberação seria de um representante de cada Câmara temática, mais os representantes da administração pública de maneira a dar operacionalidade.

\section{CONSIDERAC̣ÕES FINAIS}

O setor produtivo e a população estão no limite da capacidade de arcar com a carga tributária. A população idem. Cada vez mais, empresários, cidadãos, esperam que esse esforço ingente resulte em benefícios sociais concretos. Em suma, é necessário dar maior qualidade aos gastos públicos.

Para dar maior qualidade aos gastos públicos, identificar, definir o arcabouço legal (alguns chamam de marco regulatório) e compreende os públicos pela qual passará a política pública (stakeholders, agentes políticos, funcionários públicos) bem como os recursos materiais necessários para colocá-las em operação, é fundamental. Em seguida avaliá-la. Nesse sentido as ferramentas PDCA, SWOT podem auxiliar.

Compreender os meandros da prodigalidade legislativa também. Daí a nossa proposta no Conselho da Câmara Técnica de Unificação Legal.

Esse tema, versa mais sobre política pública do que necessariamente sobre política industrial. Mas como no nosso artigo "Consolidação Legal e Business Intelligence como Ferramentas de Política Industrial" apresentamos o tema, queríamos reforçar neste, todos os meandros por qual passa a política pública.

Propor política de desenvolvimento tecnológico e inovação, propor políticas de desenvolvimento econômico, passam por problemas semelhantes dessa prodigalidade legislativa. Compreendê-la nos ajuda entender por que tantos bons planos de políticas públicas de tecnologia, inovação desenvolvimento econômico e mesmo a política industrial podem avançar pouco.

Precisamos de empresários e pensadores inovadores e dinâmicos. 
Mas precisamos tanto quanto de pessoas que consigam pensar com grande propriedade os caminhos em que, usando todas as potencialidades do direito administrativo, transforme boas ideias em políticas públicas consistentes, impessoais e não discricionárias. Parafraseando Brecht, se inovadores na ciência, na tecnologia são imprescindíveis, inovadores capazes de primar pelos princípios da administração pública permitindo um ambiente de inovação num ambiente anti-discricionário não menos. 


\section{REFERÊNCIAS}

BRASIL. Constituição (1988). Constituição da República Federativa do Brasil. Brasília, DF: Senado, 1988.

COSTA, Domingos Barroso da. A crise do supereu e o caráter criminógeno da sociedade de consumo. 156f. Dissertação (Mestrado em Psicologia).-Programa de Pós-Graduação em Psicologia . Pontifícia Universidade Católica de Minas Gerais, Belo Horizonte, 2008. Disponível em http://www. pucminas.br/documentos/dissertacoes_domingos_barroso.pdf. Acesso em 19/04/2015.

DAgNIN0, Renato., et. al. Metodologia de Análise de Política Públicas. In: COSTA, Greiner; DAGNINO, Renato. Org. Gestão Estratégica em Políticas Públicas. Campinas,SP: Editora Alínea, 2013.

KLITGAARD, Robert. Strategies against Corruption. In: Foro Iberoamericano sobre el Combate a la Corrupción (1998 Jun. 15-16: Santa Cruz de la Sierra) CLAD; Agencia Española de Cooperación Internacional. Disponivel em http://unpanl.un.org/intradoc/groups/public/documents/clad/ clad0035403.pdf. Acessado em 08/04/2015

KOTLER, Philip; KELLER, Kevin Lane. Administração de marketing. Trad. Ricardo Bastos Vieira São Paulo: Pearson Prentice Hall, 2006.

LIJPHART, Arend. Modelos de Democracia. Desempenho e Padrões de Governo em 36 países. Trad. Roberto Franco $2^{a}$ ed. Rio de Janeiro: Civilização Brasileira, 2008.

MEIRELLES, Helly Lopes; ALEIXO; Délcio Balestero; BURLE FILHO; José Emmanoel. Direito Administrativo Brasileiro. $38^{a}$ edi. São Paulo: Malheiros Editores, 2012

SOROCABA. Lei Municipal 9672/2011,

Lei Municipal 9892/2011

Lei Municipal 9114/2010

Lei Municipal 9449/2010

Lei Municipal 10228/2012

Lei Municipal 10388/2013

Lei Municipal 5546/98

Lei Municipal 10589/2013

SABATIER, Paul. Policy Change over a Decade or More In: JENSKINS-Smith H.C.; SABATIER, Paul A. Police Change and Learning. An Advocacy Coalition Approach. Bolder-San Francisco-0xford: Westview Press, 1993.

SERAFIM, Milena P.; DIAS, Rafael. Conceitos e ferramentas para análise de Política Pública. In: BENINI, Édi. Et. al. Org. Gestão pública e sociedades: fundamentos e políticas de economia solidária São Paulo: Outras Expressões, 2011

SOUZA, Celina. Políticas Públicas: uma revisão da literatura. Sociologias, Porto Alegre, ano $8, n^{0} 16$, jul/dez 2006, p. 20-45 
